\title{
Numerical Simulation of Plasma Spraying Performance Index
}

\author{
Vasiliy Frolov ${ }^{1}$, and Yury Klochkov ${ }^{1 *}$ \\ ${ }^{1}$ National Technology Initiative Center for Advanced Manufacturing Technologies based on the \\ Institute of Advanced Manufacturing Technologies of Peter the Great St. Petersburg Polytechnic \\ University Polytechnicheskaya, 29, St.Petersburg, 195251, Russia
}

\begin{abstract}
In recent years, there has been an increasing interest in plasma jet numerical simulation. Speed and temperature propagation in axial and radial direction in plasma jet significantly influences on speed and temperature of sprayed material and therefore on coating quality. However, there are few studies concerning plasma jet numerical simulation in modern software systems and they describe a specific problem. It is a wellknown fact that using simple structural components such as plasmatron heads for plasma thermal spraying allows us to increase the quality of zirconium oxide coatings by increasing the speed of spraying particles and decreasing their spread value and allows to increase economic efficiency of the process by increasing the operation factor of spraying material. However, scientists have not studied well the influence of the plasmatron head, which looks like a cone element, and the simulation of a high temperature flow along the channel is not mentioned in publications. Therefore, it is necessary to research the flow of a high temperature current along the channel of the head.
\end{abstract}

Keywords: ANSYS, numerical simulation, plasmatron head, energy

\section{Introduction}

A rapid development of both the majority of industries and scientific research is highly connected with the implementation of the modern automation systems (Computer-aided engineering - CAE). ANSYS Inc. is one of the companies to produce CAE. The main products are the following software: ANSYS, ANSYS CFX and Fluent. ANSYS CFX is developed for the analysis of inner and outer aerodynamics. Using ANSYS CFX software in studying fluid mechanics allows to speed up the achievement of the result. That is why we managed to complete the task using ANSYS CFX.

We studied the flow of heated plasma jet with the axially symmetrical spray diffuser with $45^{\circ}$ expansion angle and without it. [1] The temperature of plasma flow for thermal spraying can be about 7000-20000K, which is much higher than the melting temperature of any material. Unfortunately, the processes of extra high level of temperatures differ

\footnotetext{
* Corresponding author: klochkov_yus@spbstu.ru
} 
significantly from those, which are carried out in room temperature. This makes the simulation much more complicated. [2]

The flow in plasmatron outlet looks like a plasma jet with $6 \mathrm{~mm}$ diameter and $770 \mathrm{~m} / \mathrm{s}$ initial speed. For our research we chose the flow area of $80 \mathrm{~mm}$ diameter and the length of $100 \mathrm{~mm}$ surrounding this jet. The jet flow was calculated by control-volume method in ANSYS CFX. The geometry of computational domain and grid was constructed in ANSYS ICEM CFD.

\section{$2 \quad$ Materials and methods}

In our study we use a structural computational grid. The grid for calculation the jet without a diffuser has 2325000 hexagonal elements. [3] The block structure and the number of grid elements along each of block sides to calculate the jet without a diffuser is shown in Fig.1. The general form of a calculation area is shown in Fig. 2-4.

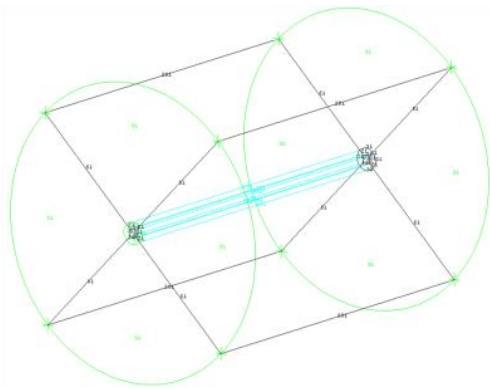

Figure 1 - The block structure of grid to calculate the jet without a diffuser.

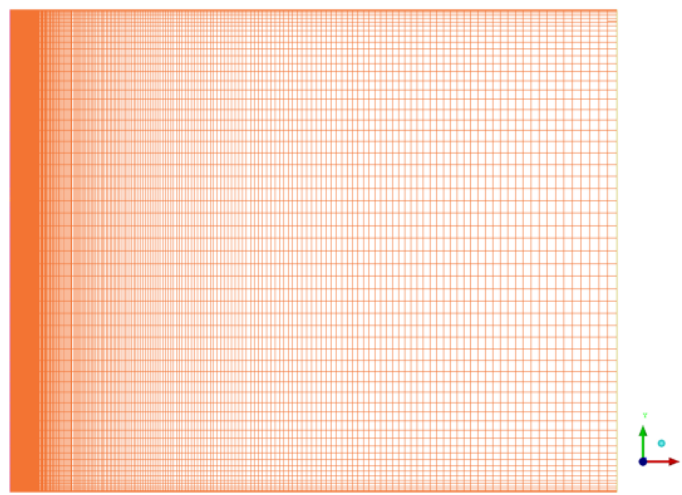

Figure 3 - Lengthwise view of calculation grid

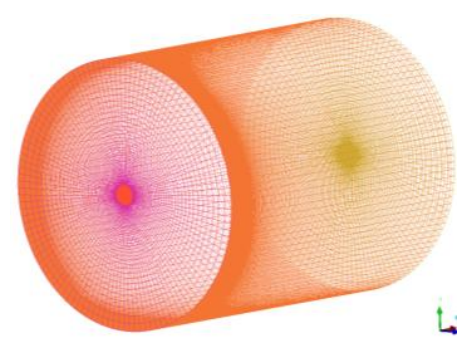

Figure 2 - The general form of grid

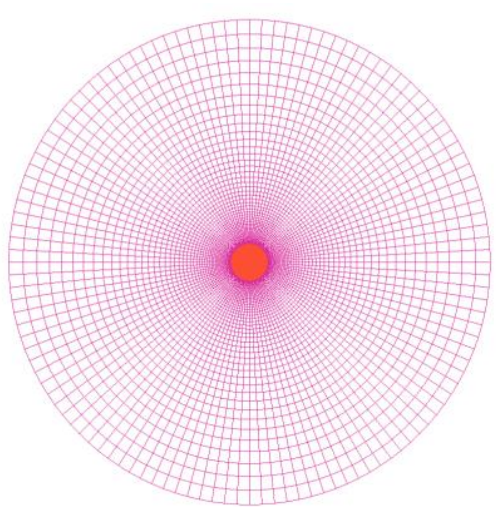

Figure 4 - Rotational view of calculation grid without a diffuser

The calculation grid with a $45^{\circ}$ expansion angle diffuser and 30mm length has 2160000 hexagonal elements. [4-5] The block structure and the number of grid elements along each of block sides to calculate the jet without a diffuser is shown in Fig. Figure 5. The general form of a calculation area is shown in Fig. 6-9. 


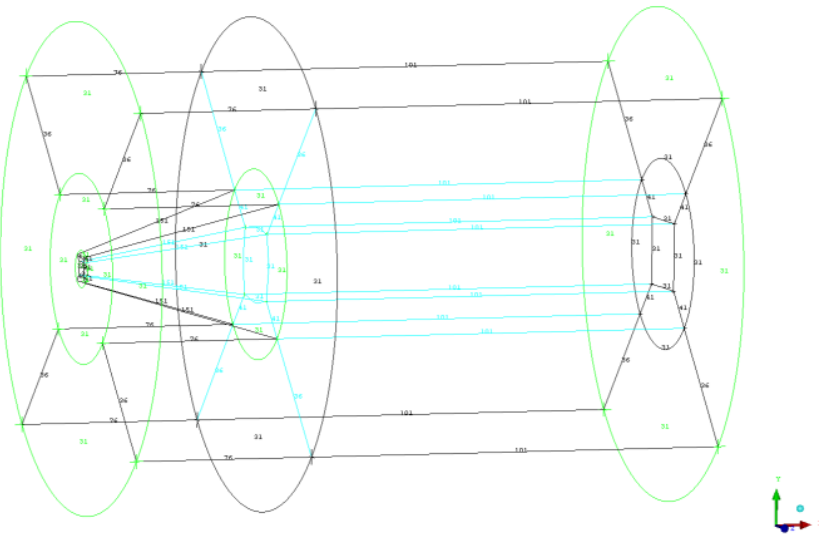

Figure 5 - The block structure of grid to calculate the jet with a diffuser

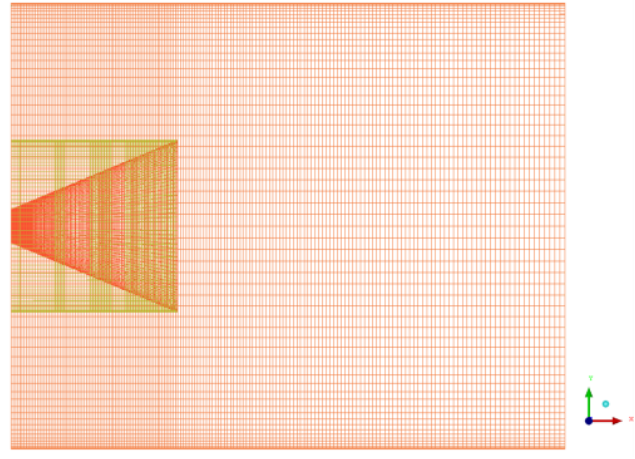

Figure 6 - Lengthwise view of calculation grid with a diffuser

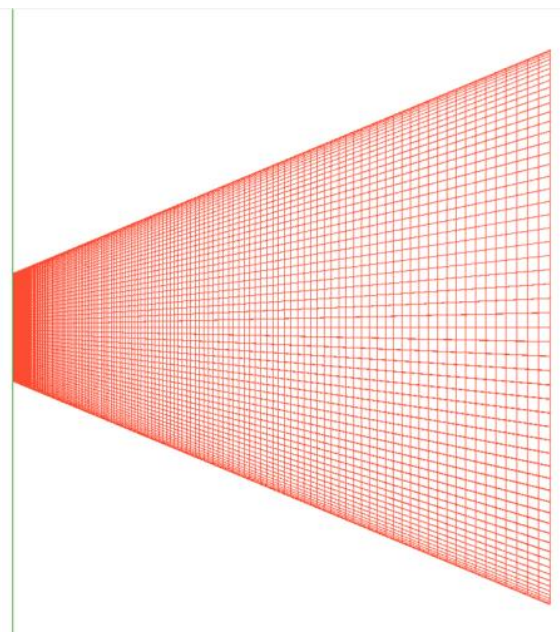

Figure 8 - Calculation grid on the diffuser side

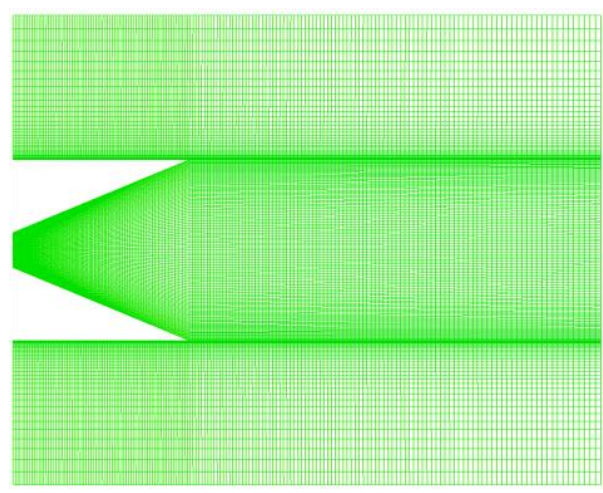

Figure 7 - Lengthwise view of calculation grid along the jet axis

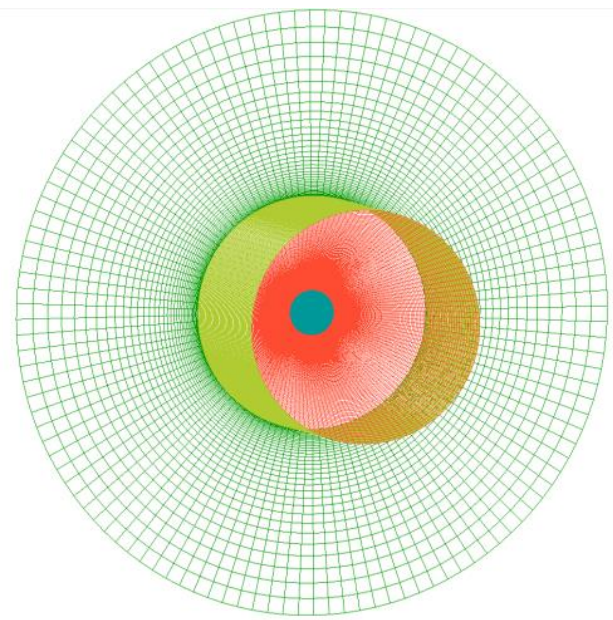

Figure 9 - The view of calculation grid from the diffuser side 
We calculated the flow in ANSYS CFX by control volume analysis using the compressible ideal gas model, enthalpy complete equation to calculate thermal transfer concerning variable density, and $\mathrm{k}-\varepsilon$ turbulence model. [6-8]

Given the jet inlet temperature equal to $10700 \mathrm{~K}$, the air velocity at inlet being $770 \mathrm{~m} / \mathrm{s}$, is lower than the sound speed (Mach number 0,3-0,4), that is why we chose the subsonic condition of jet inlet (Figure Figure 10). [7]

The area around the jet is considered as an adiabatic wall. We define other borders by ambient pressure equal to $1 \mathrm{~atm}$ and $20^{\circ} \mathrm{C}$.

The outer and inner sides of diffuser (Figure 11) [8-12] are defined as the sides without slip of boundary layer and the lack of thermal conductivity (adiabatic).

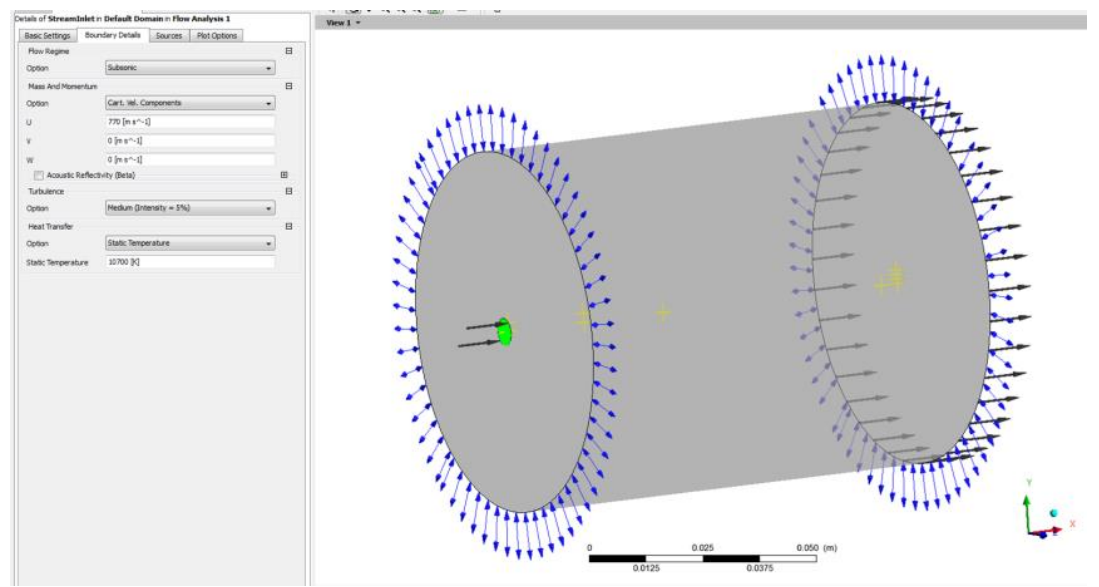

Figure 10 - Boundary conditions at the jet inlet
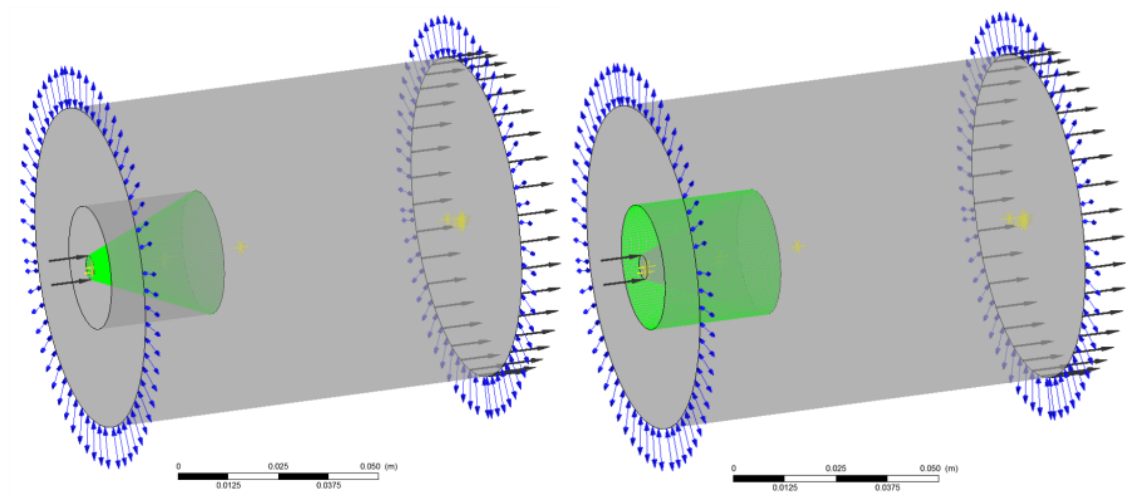

Figure 11 - The outer and inner sides of diffuser

We carried out the jet flow analysis in ANSYS CFX by quasisteady method and it goes for 1700 - 3000 iterations, which takes about 2-3 days and 9GB of core memory for each simulation case when calculating on 8 processor cores of Core $\mathrm{i} 7$.

\section{Results and discussion}

We estimated fine precision by check points, the location of which can be seen in Figure 10-11. The convergence graphs of the jet research without a head are shown in Fig. 12, and the jet research with a head - in Fig. Figure 13. However, when calculating the jet flow 
without a head after 3000 iterations the results don't match and vary along the plasmatron axis and jet flow has fractional deviation.

a)
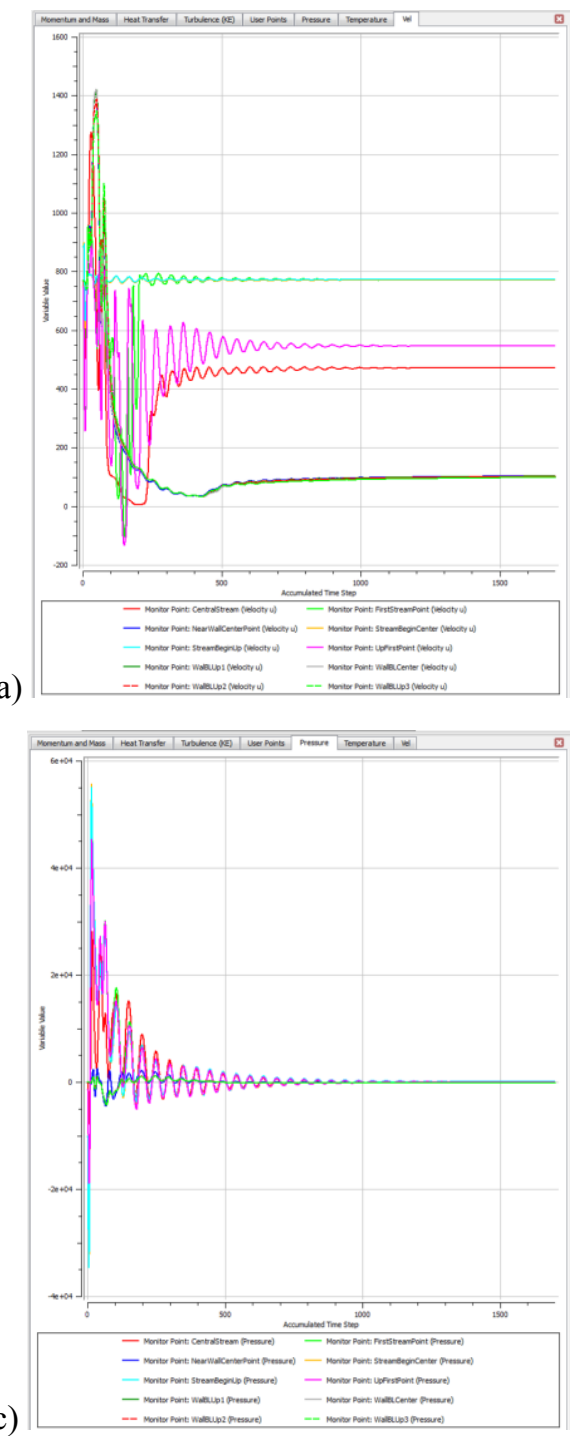

b)
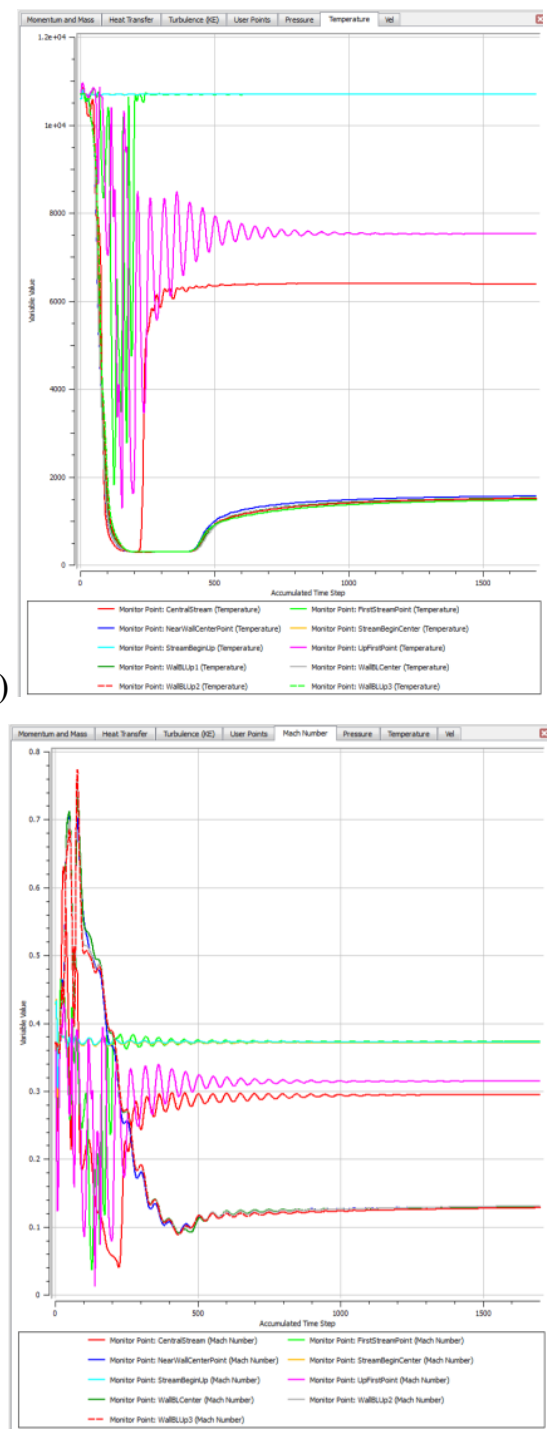

Figure 12 - The convergence graphs in check points of the jet research without a head a) velocity, b) temperature, c) pressure, d) Mach number 
a)

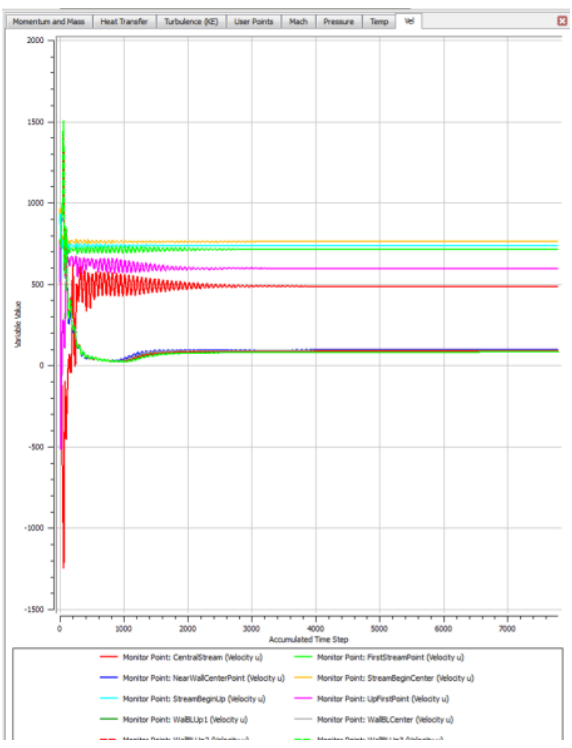

b)
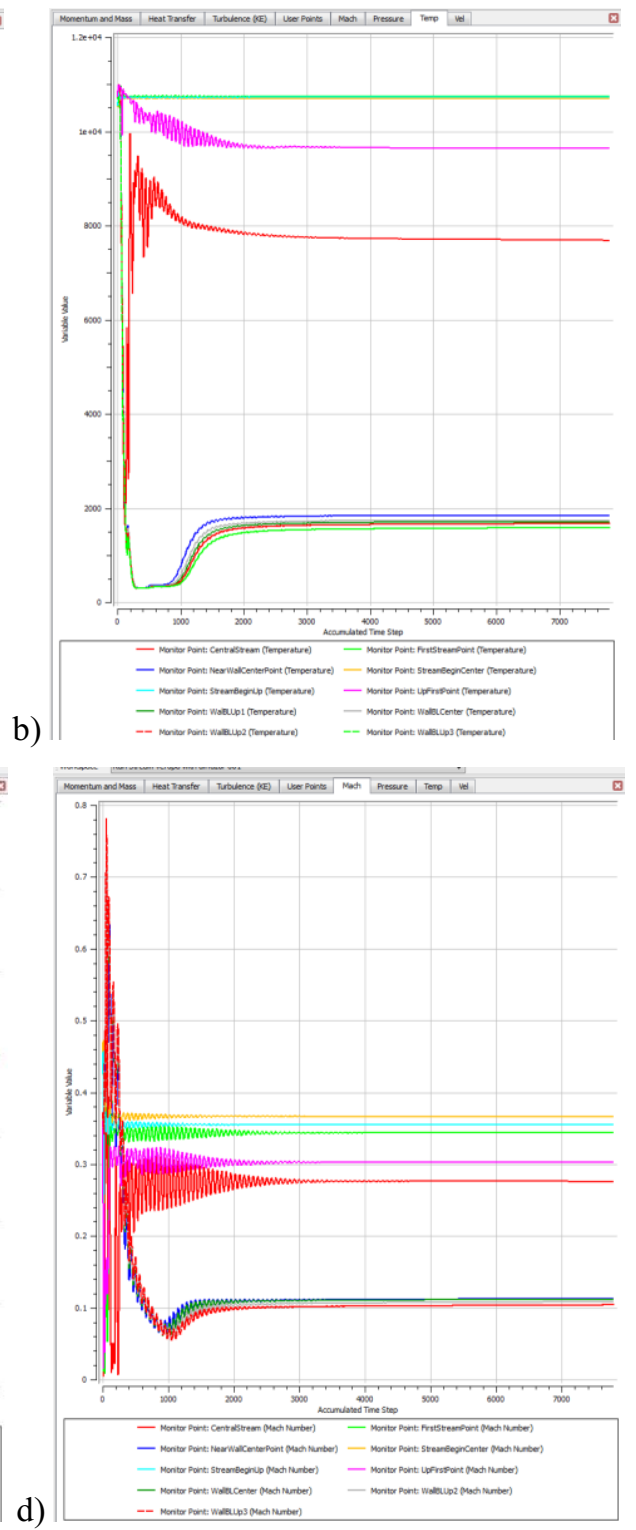

c)

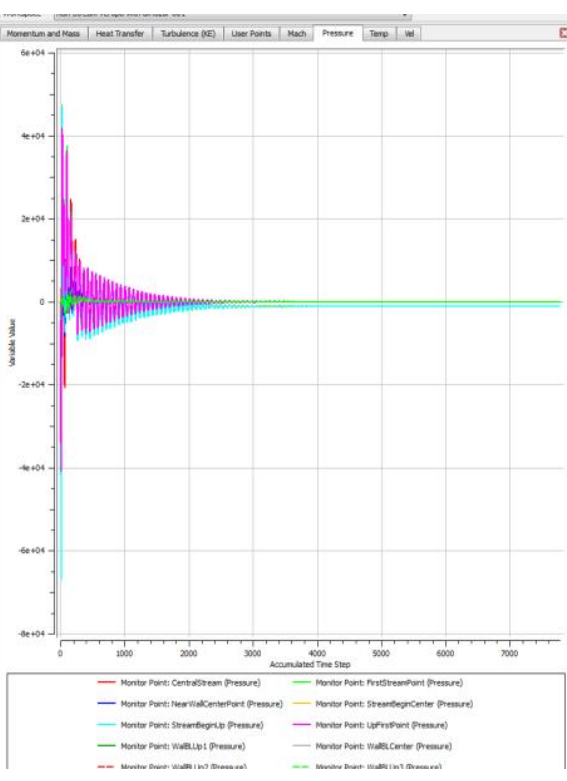

Figure 13 - The convergence graphs in check points of the jet research with a diffuser head a) velocity, b) temperature, c) pressure, d) Mach number

The velocity field comparison of the jet flow without a head and with a diffuser head is shown in Figure 14. 

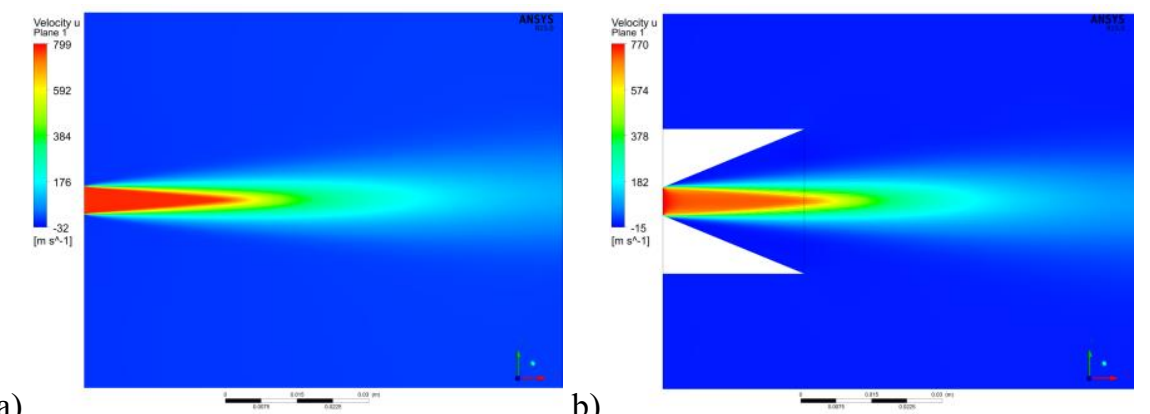

Figure 14 - Velocity fields a) without a head, b) with a diffuser head with a $45^{\circ}$ expansion angle

The temperature field comparison of the jet flow without a head and with a diffuser head is shown in Figure 15.
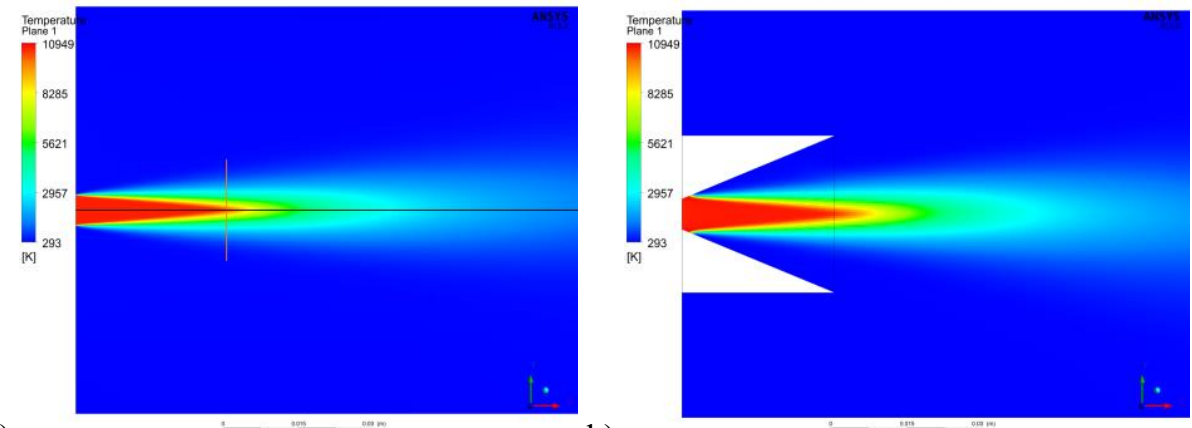

a)

b)

Figure 15 - Temperature fields a) without a head, b) with a diffuser head with a $45^{\circ}$ expansion angle

To compare a free jet flow and a jet flow through the head, we build up velocity and temperature profiles $30 \mathrm{~mm}$ off the jet outlet (Figures 16-17), and also velocity and temperature distribution along jet axis (Figures Figure 18-19).

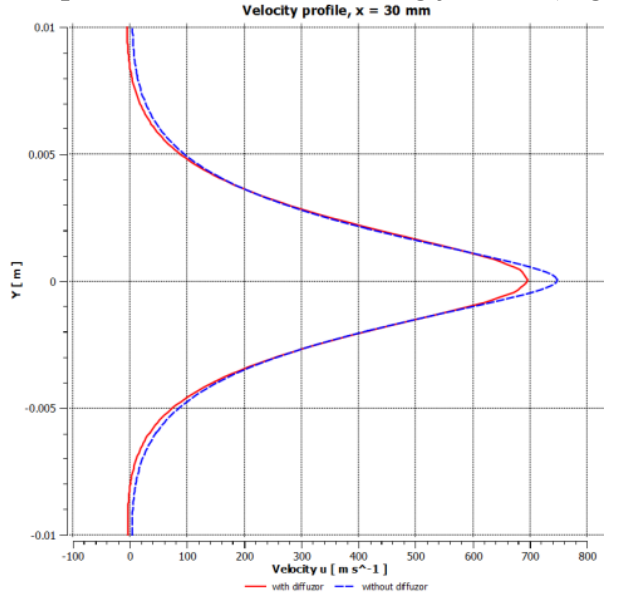

Figure 16 - Velocity profiles $30 \mathrm{~mm}$ off the jet inlet

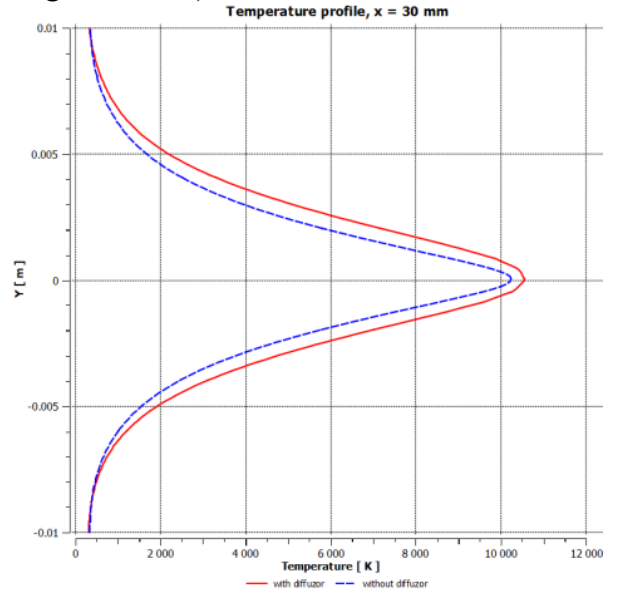

Figure 17 - Temperature profiles $30 \mathrm{~mm}$ off the jet inlet 
Graphs analysis shows that the velocity of Y-axis $30 \mathrm{~mm}$ off plasmatron almost does not change excluding the flow in the jet center, it is lower on $40-50 \mathrm{~m} / \mathrm{s}$, the reason of it is the head of plasmatron. On the other hand the $\mathrm{Y}$ axis temperature $30 \mathrm{~mm}$ off plasmatron significantly increases its range, for example the temperature of $10000 \mathrm{~K}$ without a head is fixed $0,2-0,3 \mathrm{~mm}$ off the jet axis, and with a head until $1 \mathrm{~mm}$ off the jet axis. So, using a head increases the $\mathrm{Y}$-axis temperature on the distance from 0,3 to $0,6 \mathrm{~mm}$.

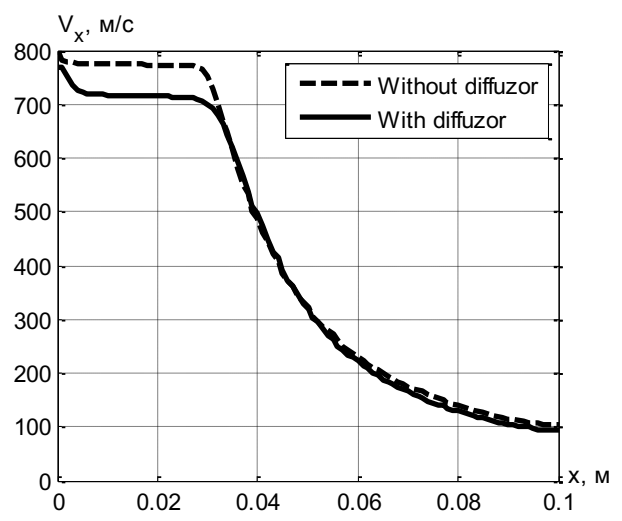

Figure 18 - Velocity distribution along jet axis

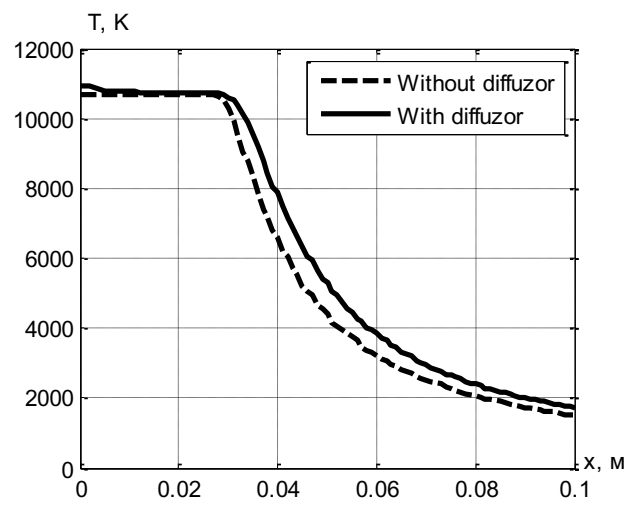

Figure 19 - Temperature distribution along jet axis

Figure 18 shows that the velocity of $\mathrm{X}$-axis using a head decreases from plasmatron front edge until the distance of $30 \mathrm{~mm}$. X-axis temperature value using a head is significantly higher from 10 to $30 \%$ on different distances.

\section{Conclusion}

During research of hypothermal gas flow, we found out that the flow has an area where the velocity and temperature remain constant, it is a jet core, and a transition area, which is the ambient air mixing area. This is useful for plasma flow mathematic simulation. We illustrated that the $\mathrm{X}$-axis velocity using a head was decreasing from plasmatron front edge until the distance of $30 \mathrm{~mm}$. X-axis temperature value using a head is significantly higher from 10 to $30 \%$ on different distances. The temperature increases across flow direction. So, using a head increases geometrical dimensions of hypothermal mixing area preventing entry of ambient air.

\section{References}

1. Bystrov, A., Vostrov, K., Frolov, V., \& Bistrov, A. (2019). The method of processing the droplet-air flow by non-equilibrium plasma. Paper presented at the E3S Web of Conferences, , 140 doi:10.1051/e3sconf/201914010004

2. Frolov, V. Y., Ivanov, D. V., \& Shibaev, M. A. (2014). Modeling the plasmachemical synthesis of nanopowdered materials using a combined plasmatron. Technical Physics Letters, 40(8), 676-679. doi:10.1134/S1063785014080185

3. Grigoriev, A. V., Razumov, N. G., Popovich, A. A., \& Samokhin, A. V. (2017). Obtaining of nb-16Si spherical powders alloy for additive technologies by 
mechanical alloying and spheroidization in electric arc discharge thermal plasma. ARPN Journal of Engineering and Applied Sciences, 12(23), 6644-6648.

4. Promakhov, V., Zhukov, A., Ziatdinov, M., Zhukov, I., Schulz, N., Kovalchuk, S Perminov, A. (2019). Inconel 625/TiB2 metal matrix composites by direct laser deposition. Metals, 9(2) doi:10.3390/met9020141

5. Subbotin, D. I., Kuznetsov, V. E., Litvyakova, A. I., Cherepkova, I. A., Surov, A. V., Nakonechnyi, G. V., \& Spodobin, V. A. (2017). Investigations of products of copper electrode erosion in an AC plasmatron. Technical Physics, 62(11), 16391642. doi:10.1134/S1063784217110275

6. Klopotov, A. A., Ivanov, Y. F., Potekaev, A. I., Abzaev, Y. A., Kalashnikov, M. P., Chumaevskii, A. V., . . Klopotov, V. D. (2020). The use of low-temperature plasma in a combined technology for the formation of wear-resistant boroncontaining coatings. Surface and Coatings Technology, 389 doi:10.1016/j.surfcoat.2020.125576

7. Kotelnikov, V. A., Kotelnikov, M. V., \& Filippov, G. S. (2020). Flat-probe diagnostic methods for collisional plasma flowing from technological plasmatrons. Journal of Machinery Manufacture and Reliability, 49(1), 80-85. doi:10.3103/S1052618820010082

8. Kuptsov, A. V., Volzhenin, A. V., Labusov, V. A., \& Saprykin, A. I. (2020). Steel analysis by atomic emission spectrometry using a two-jet arc plasmatron with spark ablation. Journal of Analytical Atomic Spectrometry, 35(11), 2600-2605. doi:10.1039/d0ja00313a

9. Matushkin, A. V., Anakhov, S. V., \& Pyckin, Y. A. (2020). Study of the processes of high temperature material heating for plasma recycling doi:10.4028/www.scientific.net/MSF.989.775

10. Rakhadilov, B. K., Kenesbekov, A. B., Kowalevski, P., Ocheredko, Y. A., \& Sagdoldina, Z. B. (2020). Development of air-plasma technology for hardening cutting tools by applying wear-resistant coatings. News of the National Academy of Sciences of the Republic of Kazakhstan, Series of Geology and Technical Sciences, 3(441), 54-62. doi:10.32014/2020.2518-170X.54

11. Schiller, S., Heisig, U., \& Goedicke, K. (2020). ROLE OF PLASMATRON/MAGNETRON SYSTEMS IN PHYSICAL VAPOR DEPOSITION TECHNIQUES. Thin Solid Films Pap Presented at the Int Conf on Metall Coat San Francisco Calif Apr 3-7 1978, 54(1), 33-47. doi:10.1016/00406090(78)90274-2

12. Trenchev, G., \& Bogaerts, A. (2020). Dual-vortex plasmatron: A novel plasma $\begin{array}{llll}\text { source for CO2conversion. Journal } & \end{array}$ Utilization, 39 doi:10.1016/j.jcou.2020.03.002 